\title{
Kinetic and Thermodynamic Analysis of Guaiacol Hydrodeoxygenation
}

\author{
Alexandrina Sulman ${ }^{1} \cdot$ Päivi Mäki-Arvela ${ }^{1} \cdot$ Louis Bomont $^{1} \cdot$ Moldir Alda-Onggar $^{1} \cdot$ Vyacheslav Fedorov $^{1} \cdot$ \\ Vincenzo Russo ${ }^{2} \cdot$ Kari Eränen ${ }^{1} \cdot$ Markus Peurla $^{3} \cdot$ Uliana Akhmetzyanova $^{4} \cdot$ Lenka Skuhrovcová $^{4}$. \\ Zdeněk Tišler $^{4} \cdot$ Henrik Grénman ${ }^{1} \cdot$ Johan Wärnå $^{1} \cdot$ Dmitry Yu. Murzin ${ }^{1}$ (1)
}

Received: 18 April 2019/Accepted: 30 May 2019/Published online: 12 June 2019

(C) The Author(s) 2019

\begin{abstract}
Kinetics of guaiacol hydrodeoxygenation (HDO) was studied using supported $\mathrm{Mo}_{\mathrm{x}} \mathrm{C}-\mathrm{SBA}-15$ and as a comparison $5 \mathrm{wt} \%$ $\mathrm{Pt} / \mathrm{C}$ under 30 bar hydrogen at $200{ }^{\circ} \mathrm{C}$ and $300{ }^{\circ} \mathrm{C}$. Catalyst characterization was done by a range of physical methods including also determination of the amount of coke and the nature of adsorbed species. Pt/C gave 2-methoxycyclohexanol as the main product, whereas $\mathrm{Mo}_{2} \mathrm{C}-\mathrm{SBA}-15$ promoted direct deoxygenation exhibiting also strong adsorption of guaiacol on the catalyst surface and formation of oligomers. Thermodynamics of guaiacol HDO was elucidated and the reaction network was proposed based on which kinetic modelling was done.
\end{abstract}

\section{Graphic Abstract}

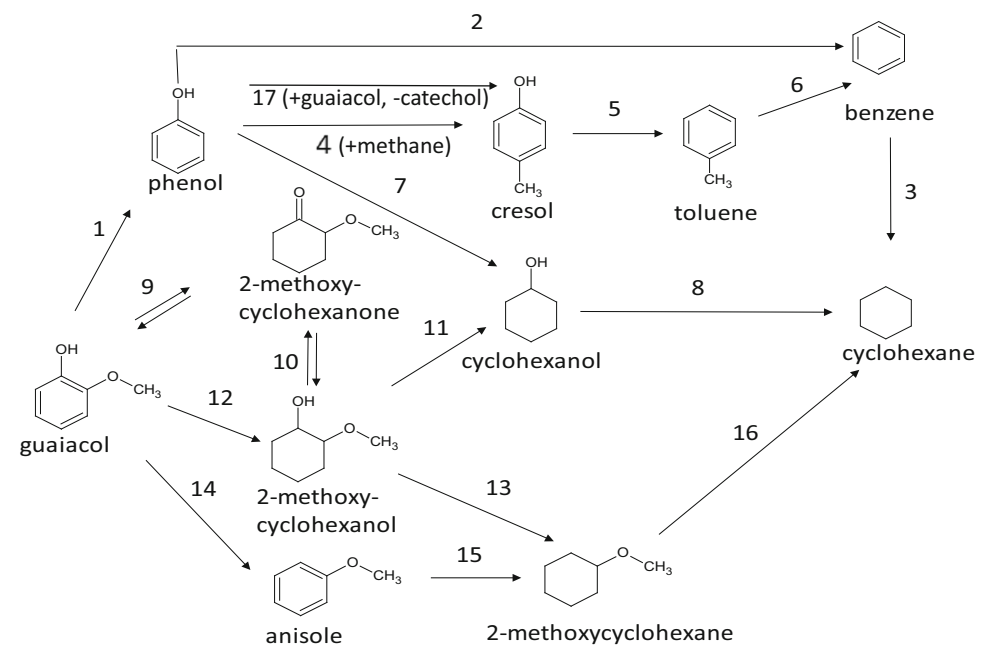

Keywords Guaiacol · Hydrodeoxygenation · Carbide $\cdot$ Kinetics $\cdot$ Thermodynamics

Dmitry Yu. Murzin

dmurzin@abo.fi

1 Johan Gadolin Process Chemistry Centre, Åbo Akademi University, Turku, Finland

2 Università di Napoli Federico II, Via Cintia, 4. IT-80126, Naples, Italy

3 University of Turku, Turku, Finland

4 Unipetrol Centre for Research and Education (UniCRE), Chempark Litvínov, Block 2838, 43670 Litvínov-Záluží 1, Czech Republic

\section{List of Symbols}

$K_{j}^{0} \quad$ Equilibrium constant at standard conditions for reaction $j$

$n \quad$ Moles (mol)

$P \quad$ Pressure (bar)

$P^{0} \quad$ Standard pressure (bar)

$R \quad$ Ideal gas constant $(\mathrm{J} / \mathrm{K} / \mathrm{mol})$

$T$ Absolute temperature $(\mathrm{K})$

$T^{0} \quad$ Absolute standard temperature $(\mathrm{K})$ 


\section{Greek Symbols}

$\Delta G_{f}^{0} \quad$ Gibbs free energy of formation at standard conditions $(\mathrm{J} / \mathrm{mol})$

$\Delta G_{r}^{0} \quad$ Gibbs free energy of reaction at standard conditions $(\mathrm{J} / \mathrm{mol})$

$\Delta G_{r, j}^{\Phi} \quad$ Gibbs free energy of reaction at 1 bar and a chosen temperature $(\mathrm{J} / \mathrm{mol})$

$\Delta G_{r, j} \quad$ Gibbs free energy of reaction at a fixed temperature and pressure $(\mathrm{J} / \mathrm{mol})$

$\Delta H_{f}^{0} \quad$ Enthalpy of formation at standard conditions $(\mathrm{J} / \mathrm{mol})$

$\Delta H_{r}^{0} \quad$ Enthalpy of reaction at standard conditions $(\mathrm{J} / \mathrm{mol})$

$v_{i, j} \quad$ Stoichiometric matrix composed by $i$ components and $j$ reactions (-)

\section{Introduction}

Biomass has been recently used as a cheap and abundant raw material for production of fuels and chemicals, for example via pyrolysing woody biomass and extraction of lignin to obtain among other products large amounts of phenolic compounds. Such compounds are not suitable directly as fuels due to their high oxygen content thus requiring deoxygenation. Bio-oil obtained by wood pyrolysis has a low $\mathrm{pH}$, is unstable and contains some catalyst poisons. Subsequently catalytic deoxygenation is far from being straightforward. Upgrading of bio-oil and lignin extracts via hydrodeoxygenation (HDO) is currently under intensive research [1-26] with both real bio-oil as well as model compounds used as a feedstock.

HDO of guaiacol in particular has been intensively investigated recently using, for example, $\mathrm{Fe} / \mathrm{SiO}_{2}$ [20], $\mathrm{Mo}_{2} \mathrm{~N}$ [3, 4], $\mathrm{Mo}_{2} \mathrm{C} / \mathrm{CNF}[2,13], \mathrm{MoC} / \mathrm{AC}$ [16], $\mathrm{Mo}_{2} \mathrm{C} / \mathrm{AC}$ [6], $\mathrm{W}_{2} \mathrm{C} / \mathrm{CNF}$ [13], $\mathrm{Ni} / \mathrm{ZrO}_{2}$ [23], $\mathrm{NiP} / \mathrm{SiO}_{2}$ [25], $\mathrm{ReO}_{\mathrm{x}}$ [5], $\mathrm{Au} / \mathrm{TiO}_{2}$ and $\mathrm{Au}-\mathrm{Rh} / \mathrm{TiO}_{2}$ [17], $\mathrm{Pt} / \mathrm{C}$ [8], Pt/alumina silicate [10], PtPd-Al-HMS [26], PtPd- $\mathrm{ZrO}_{2}-\mathrm{SiO}_{2}$, [26] $\mathrm{Ru} / \mathrm{C}$ [1], $\mathrm{Ru}-\mathrm{TiO}_{2}-\mathrm{ZrO}_{2}$ [15], $\mathrm{Rh} / \mathrm{ZrO}_{2}$ combined with alumina silicate [12] as catalysts. HDO is a complex process involving several parallel and consecutive reaction steps, e.g. demethoxylation $(1,11,16)$, dehydroxylation $(2$, $8,13,14)$, alkylation (4) and hydrogenation $(3,7,12,15)$ (Scheme 1; Table 1). Scheme 1 contains different reactions, which can be present during HDO depending on the reaction conditions and catalysts. For example, formation of cresol from phenol can occur through alternative pathways (methanation, reaction 4) and transalkylation with guaiacol giving cresol and catechol (reaction 17). The latter reaction proceeds through a surface methoxide intermediate.

The benefits of using carbides and nitrides as catalysts are their lower prices, moreover nitrides and carbides exhibit also metal-like properties [27]. However, synthesis of carbides and nitrides requires high temperatures, in the

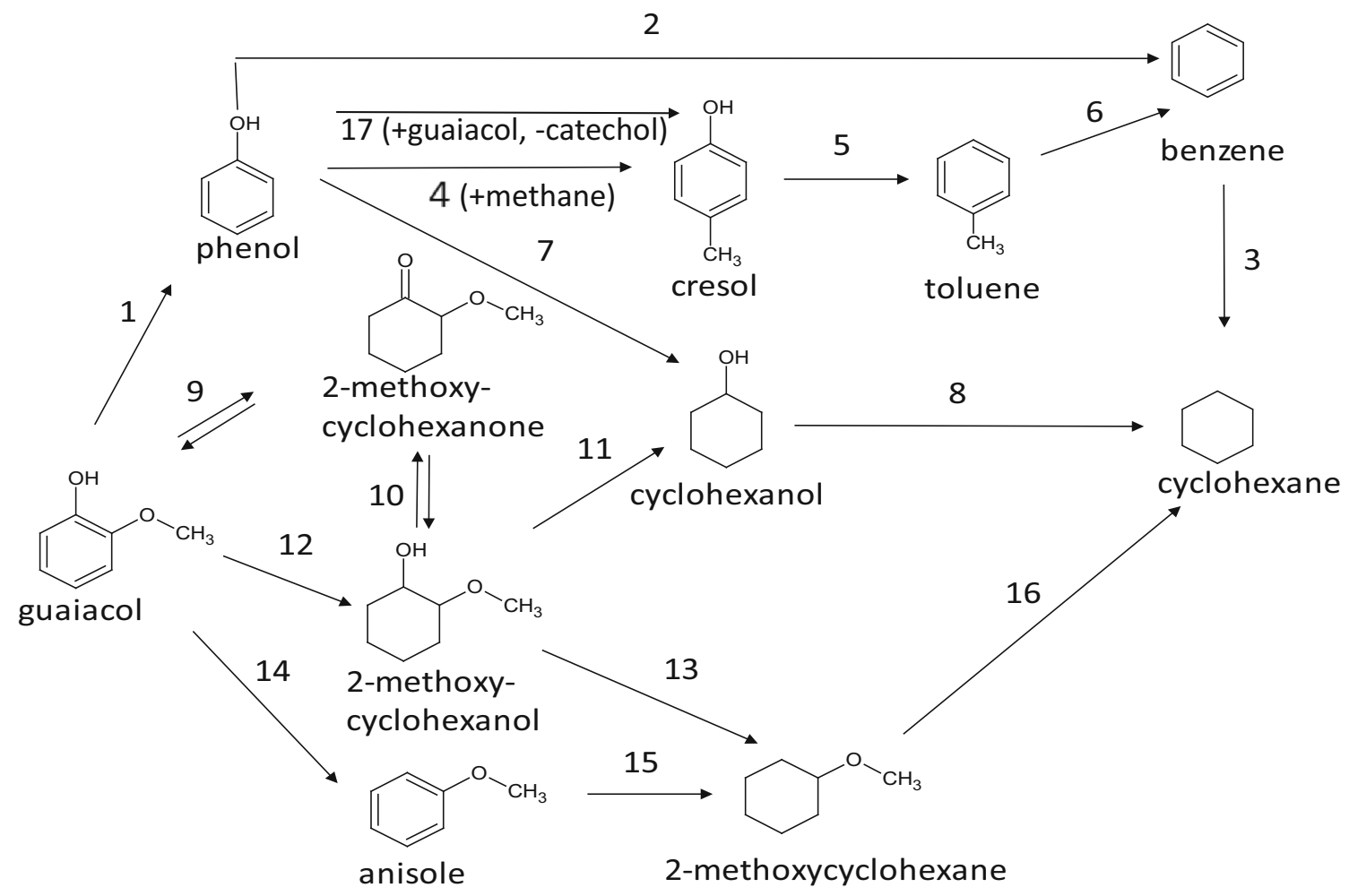

Scheme 1 Reaction scheme for guaiacol transformation based on [4, 12-14] 
Table 1 Different reactions in Scheme 1

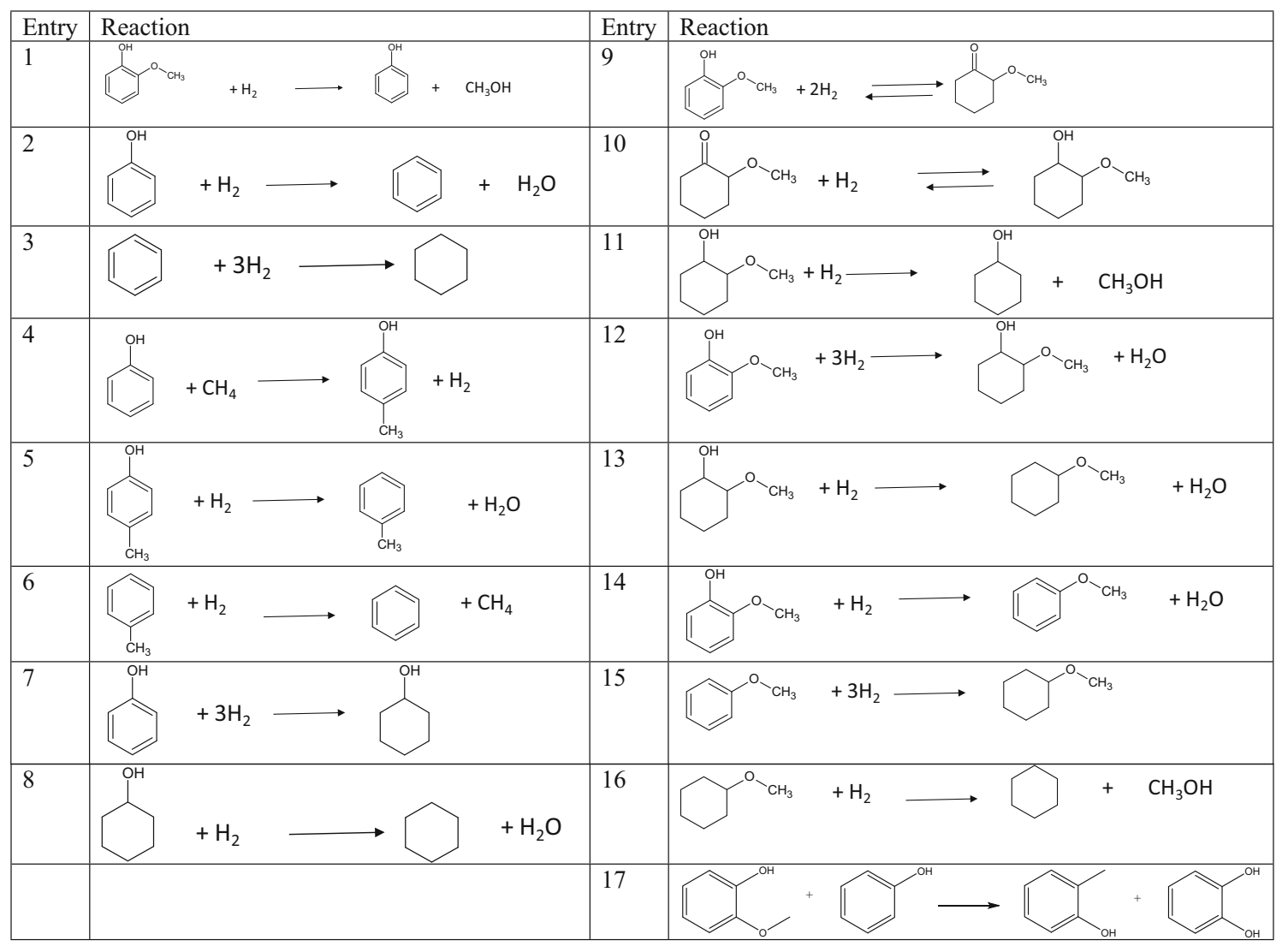

range of $700-1000{ }^{\circ} \mathrm{C}$, giving typically materials with low specific surface area. For this reason, also supported carbides have been recently prepared and tested as catalysts $[3,13]$.

Guaiacol HDO is typically performed in the temperature range of $250-50{ }^{\circ} \mathrm{C}$ under hydrogen pressure varying from 20 to 55 bar (Table 2) $[1,4,5,10,12-14,17,24]$.

The results show that the main product is phenol when molybdenum and tungsten carbides are used as catalysts $[4,13]$, whereas supported $\mathrm{Ni}$ and $\mathrm{ReO}_{\mathrm{x}}$ catalysts gave cyclohexane as the main product $[5,24]$. Several metal supported catalysts, such as $\mathrm{TiO}_{2}-\mathrm{Pd}-\mathrm{SiO}_{2}, \mathrm{Rh} / \mathrm{ZrO}_{2}$ and $\mathrm{Au}-\mathrm{Rh} / \mathrm{TiO}_{2}$ afforded also the deoxygenated product, cyclohexane [12, 14, 17], whereas $\mathrm{Pt} / \mathrm{C}$ catalyzed only phenyl ring hydrogenation giving 2-methoxycyclohexanol as the main product [10].

Because catalyst deactivation can be a serious issue in HDO of lignin derived substituted phenols, a special emphasis in the current work was put on the mass balance closure. The latter is typically represented through the sum of the masses of reactant and products in the liquid phase determined by GC. Another issue related to the mass balance closure is analysis of the spent catalyst giving, in particular, information about adsorption of organic compounds on the catalyst surface and coking. Coke analysis has been scarcely reported in guaiacol $\operatorname{HDO}[8,19,25]$. One example is temperature programmed oxidation of spent $\mathrm{Ni}_{2} \mathrm{P} / \mathrm{SiO}_{2}$ catalyst showing formation of $\mathrm{CO}$ and $\mathrm{CO}_{2}$ mostly at ca. $460{ }^{\circ} \mathrm{C}$ [25]. Thermogravimetric analysis performed for the spent catalyst used in the gas-phase guaiacol HDO can be also mentioned showing ca. 20\% weight loss in the case of $\mathrm{Pt} / \mathrm{C}$ catalyst [8]. Coke was also estimated in gas phase $\mathrm{HDO}$ of guaiacol using $\mathrm{Ni}$ - and $\mathrm{Fe}-$ based commercial catalysts [19]. In the current work size exclusion chromatography (SEC) was used to qualitatively confirm the presence of oligomers. Even if oligomer analysis has been applied very rarely in the literature, one example related to HDO of bio-oil is worth mentioning [31] when gel permeation chromatography was utilized to analyze macromolecules.

Kinetics of guaiacol transformation in batch reactors has been very scarcely reported including reactions over $\mathrm{W}_{2} \mathrm{C} /$ $\mathrm{CNF}, \mathrm{Mo}_{2} \mathrm{C} / \mathrm{CNF}$ [13], $\mathrm{Mo}_{2} \mathrm{~N}$ [3] and $\mathrm{ReO}_{\mathrm{x}}$ [5]. From the discussion above it can be concluded that while molybdenum nitride and carbide have been used in guaiacol HDO, the literature is void from the data for supported $\mathrm{Mo}_{2} \mathrm{C}$ on 
Table 2 Literature data on guaiacol hydrodeoxygenation

\begin{tabular}{|c|c|c|c|c|c|c|c|}
\hline Catalyst & Solvent & $\begin{array}{l}\mathrm{T} \\
\left({ }^{\circ} \mathrm{C}\right)\end{array}$ & $\begin{array}{l}\text { Pressure } \\
\text { (bar) }\end{array}$ & Conversion $(\%) /$ time $(\mathrm{h})$ & Main product & $\begin{array}{l}\text { Yield, Y }(\%) \text { or } \\
\text { selectivity, S }(\%)\end{array}$ & References \\
\hline $\mathrm{W}_{2} \mathrm{C} / \mathrm{CNF}$ & Dodecane & 350 & 55 & $88 / 6$ & Phenol & $S=49$ & {$[13]$} \\
\hline $\mathrm{Mo}_{2} \mathrm{C} / \mathrm{CNF}$ & Dodecane & 350 & 55 & $100 / 6$ & Phenol & $\mathrm{S}=38$ & [13] \\
\hline $\mathrm{MoN} / \mathrm{C}$ & Decalin & 300 & 50 & $48 / 6$ & Phenol & $\mathrm{Y}=28$ & [4] \\
\hline $\mathrm{Mo} / \mathrm{C}$ & No solvent & 350 & 40 & $\begin{array}{l}\text { 92/Continuous mode, space } \\
\text { time }=0.068 \mathrm{~h}\end{array}$ & Phenol & $Y=45$ & [1] \\
\hline $\begin{array}{c}\mathrm{Ni} / \mathrm{SiO}_{2-} \\
\mathrm{ZrO}_{2}\end{array}$ & Dodecane & 300 & 50 & $88 / 5$ & Cyclohexane & $S=90$ & {$[24]$} \\
\hline $\mathrm{ReO}_{\mathrm{x}} / \mathrm{CNF}$ & Dodecane & 300 & 50 & $98 / 6$ & Cyclohexane & $Y=65$ & {$[5]$} \\
\hline $\mathrm{Pt} / \mathrm{C}$ & Hexadecane & 259 & 30 & $87 / 1$ & 2- & $Y=80$ & {$[10]$} \\
\hline $\begin{array}{l}\mathrm{TiO}_{2}-\mathrm{Pd} / \\
\mathrm{SiO}_{2}\end{array}$ & Dodecane & 300 & 20 & $\begin{array}{l}\text { 100/Continuous mode, weight } \\
\text { hour space velocity }=24 \mathrm{~h}^{-1}\end{array}$ & Cyclohexane & $Y=63$ & [14] \\
\hline $\mathrm{Au}-\mathrm{Rh} / \mathrm{TiO}_{2}$ & Gas phase & 280 & 40 & 94/Continuous mode & Cyclohexane & $Y=62$ & [17] \\
\hline $\begin{array}{c}\mathrm{Rh} / \mathrm{ZrO}_{2-} \\
\text { alumino } \\
\text { silicate }\end{array}$ & Decane & 310 & 40 & Not determined & Cyclohexane & $Y=68$ & {$[12]$} \\
\hline
\end{tabular}

mesoporous supports. The aim in this work was thus to investigate kinetics of guaiacol transformation over $40 \mathrm{wt} \% \mathrm{Mo}_{2} \mathrm{C} / \mathrm{SBA}-15$ prepared from hexamethylenetetramine ammonium heptamolybdate as a precursor. Mesoporous silica SBA-15 with the cavity size larger than $6 \mathrm{~nm}$ [28] was selected as it can be expected that $\mathrm{Mo}_{2} \mathrm{C}$ would be well dispersed affording easier diffusion of the reacting molecules to the active sites. $\mathrm{Mo}_{2} \mathrm{C} / \mathrm{SBA}-15$ has been prepared previously from $\mathrm{MoO}_{3} / \mathrm{SBA}-15$ via the temperature programmed carburization method [29].

The novelty in this work regarding the materials is that $\mathrm{Mo}_{2} \mathrm{C} / \mathrm{SBA}-15$ has been prepared using hexamethylenetetramine ammonium heptamolybdate complex as a precursor while this precursor has been earlier used in the synthesis of $\mathrm{Mo}_{2} \mathrm{C}$ [30]. According to our knowledge $\mathrm{Mo}_{2} \mathrm{C} / \mathrm{SBA}-15$ has not been investigated as a catalyst in HDO of phenolic lignin derived model compounds. As a benchmark catalyst $\mathrm{Pt} / \mathrm{C}$ was used to compare its behavior with molybdenum carbide. In addition to kinetic studies also thermodynamics of guaiacol HDO, not previously reported, was explored using the Gibbs-Helmholtz equation [32].

\section{Experimental}

Mesoporous silica with the SBA-15 structure was synthesized following the method reported by Zukal et al. [33]. Tetraethyl orthosilicate (TEOS) was used as a silica source; amphiphilic triblock copolymer P123 was applied as a structure directing agent. Synthesis of SBA-15 was performed at $95{ }^{\circ} \mathrm{C}$ during $66 \mathrm{~h}$. The resulting solid was recovered by filtration, extensively washed with distilled water and dried at $80{ }^{\circ} \mathrm{C}$ overnight. The template was removed by calcination in air at $540{ }^{\circ} \mathrm{C}$ for $8 \mathrm{~h}$ (with the temperature ramp of $1{ }^{\circ} \mathrm{C} / \mathrm{min}$ ). Calcined extrudates were crushed using a laboratory jaw crusher and sieved to obtain a fraction 560 to $850 \mu \mathrm{m}$ (Retsch AS 300).

The supported catalyst was prepared by the incipient wetness impregnation method from hexamethylenetetramine molybdate complex (HMT-AHM). The latter was synthesized according to the method reported by Afanasiev [34], who dissolved $86 \mathrm{~g}$ of hexamethylenetetramine (HMT) and $50 \mathrm{~g}$ of ammonium heptamolybdate (AHM) in $400 \mathrm{~mL}$ and $300 \mathrm{~mL}$ distilled water, respectively. Thereafter, these solutions were mixed and the final solution was left in air at ambient conditions overnight resulting in precipitation of crystals. These crystals were filtered using a filter paper and washed with deionized water, followed by drying in air at ambient temperature for 3 days. The incipient wetness method was used to impregnate the HMT-AHM precursor on the support (2 g SBA-15) followed by drying at $120^{\circ} \mathrm{C}$ overnight. This catalyst was carburized with the same method as described above.

Temperature programmed reduction was done in the flow of a gas mixture of $20 \mathrm{vol} \% \mathrm{CH}_{4}$ in $\mathrm{H}_{2}$ (the flow rate $75 \mathrm{~mL} / \mathrm{min}$ ) during $3 \mathrm{~h}$ at $700{ }^{\circ} \mathrm{C}$ (the temperature ramp of $10{ }^{\circ} \mathrm{C} / \mathrm{min}$ ) with further passivation of the final material with the mixture of 1 vol. $\% \mathrm{O}_{2}$ in $\mathrm{Ar}(75 \mathrm{~mL} / \mathrm{min}$ during $2 \mathrm{~h})$.

$40 \mathrm{wt} \% \mathrm{Mo}_{\mathrm{x}} \mathrm{C}-\mathrm{SBA}-15$ was reduced in pure $\mathrm{H}_{2}$ (flow rate $\sim 50 \mathrm{~mL} / \mathrm{min}$ ) at $450{ }^{\circ} \mathrm{C}$ (heating rate $5{ }^{\circ} \mathrm{C} / \mathrm{min}$ ) for 
$13 \mathrm{~h}$ and cooled down to $170{ }^{\circ} \mathrm{C}$ under $\mathrm{H}_{2}$ flow and flushed with Ar for $5 \mathrm{~min}$. About 10-15 g of a solvent was introduced to the reduced catalyst under Ar flow to avoid oxidation. The catalyst was stored in the solvent overnight prior to its use.

\subsection{Catalyst Characterization Methods}

Thermogravimetric analysis of the fresh and the spent catalysts was performed under nitrogen using SDT Q600 (V20.9 Build 20) instrument. About 6-8 mg of the sample was weighed, put in a platinum pan and heated from room temperature to $625^{\circ} \mathrm{C}$ with a $10{ }^{\circ} \mathrm{C} / \mathrm{min}$ ramp. The purge gas feed rate into the system was $100 \mathrm{~mL} / \mathrm{min}$.

The synthesised catalyst was characterized by X-ray powder diffraction (XRD) analysis performed with X-ray diffractometer D8 Advance Eco (Bruker AXS) equipped with SSD 160 detector using $\mathrm{Cu} \mathrm{K} \alpha$ emission at $\lambda=1.54 \AA$. XRD patterns were collected in the range of $2 \theta$ values from $5^{\circ}$ to $70^{\circ}(0.021 \%$ step, integration time of $0.5 \mathrm{~s}$ per step). The X-ray tube voltage was set to $40 \mathrm{kV}$ and the current to $25 \mathrm{~mA}$. Diffraction data were evaluated using the Diffrac.Eva V 4.1.1 software. Subsequently, crystalline phases were identified according to the Powder Diffraction database of the International Centre for Diffraction Data (ICCD PDF2).

The textural properties were characterized by $\mathrm{N}_{2}$-adsorption (BET) at $77 \mathrm{~K}$ performed with the gas sorption analyzer-Autosorb-iQ (Quantachrome Instruments).

In order to examine the catalyst morphology transmission electron microscopy (TEM) using JEM 1400 plus (JEOL) was applied. The acceleration voltage of $120 \mathrm{kV}$ and the resolution of $0.98 \mathrm{~nm}$ for Quemsa II MPix bottom mounted digital camera were used. Scanning electron microscopy (Zeiss Leo Gemini 1530) was used to determine the crystal morphology.

Ammonia TPD was performed using Autochem 2910 with the following temperature program: heating to $450{ }^{\circ} \mathrm{C}$ for $1 \mathrm{~h}$, flushing the catalyst at $450{ }^{\circ} \mathrm{C}$ with helium, cooling to $100{ }^{\circ} \mathrm{C}$-ammonia adsorption at $100{ }^{\circ} \mathrm{C}$ for $60 \mathrm{~min}$, flushing chemisorbed ammonia away with helium flow at $100{ }^{\circ} \mathrm{C}$ and then starting the temperature ramp $10{ }^{\circ} \mathrm{C} / \mathrm{min}$ to $900{ }^{\circ} \mathrm{C}$. The outlet was connected to $\mathrm{MS}$ recording the response from ammonia, water and $\mathrm{CO}$.

Coke was extracted from the selected spent catalysts using heptane as a solvent similar to [35]. The extraction was performed by refluxing the catalyst, $10 \mathrm{mg}$ in heptane solution, $10 \mathrm{~mL}$, for $4 \mathrm{~h}$ under stirring.

\subsection{Catalytic Tests and Analysis of Reaction Mixture}

The reactions were carried out in $300 \mathrm{~mL}$ batch reactor (Parr Instruments) equipped with a stirrer and a sampling line (with a $5 \mu \mathrm{m}$ filter in order to take only the liquid from the reactor) and cooling water circulation. The reactor was surrounded by an electrical heater. Argon (AGA 99.999\%) and hydrogen (AGA 99.999\%) gas bottles were coupled to the reactor system. The stirring speed during the reaction was $900 \mathrm{rpm}$ to avoid external mass transfer limitations.

In a typical experiment the liquid volume was $50 \mathrm{~mL}$, dodecane was used as a solvent together with $100 \mathrm{mg}$ of the reactant and $50 \mathrm{mg}$ of a catalyst. Two temperature levels, $200{ }^{\circ} \mathrm{C}$ and $300{ }^{\circ} \mathrm{C}$ were selected for investigations while the total pressure of 30 bar was used in all experiments. Hydrogen partial pressures were at $200{ }^{\circ} \mathrm{C}$ and $300{ }^{\circ} \mathrm{C} 29.3$ bar and 24.8 bar, respectively.

$40 \mathrm{wt} \% \mathrm{Mo}_{\mathrm{x}} \mathrm{C} / \mathrm{SBA}-15$ was pre-reduced prior to experiments, while the commercial reference catalyst 5 wt\% Pt/C (Degussa, F106, XKYF/W) was used without any prereduction. Total pressure of 30 bar was used also in the latter case.

The samples taken at different times from the reactor were analyzed by gas chromatography using DB-1 capillary column (Agilent 122-13e) with the length of $30 \mathrm{~m}$, internal diameter of $250 \mu \mathrm{m}$ and the film thickness of $0.50 \mu \mathrm{m}$. The flow rate of helium was $1.9 \mathrm{~mL} / \mathrm{min}$. The following temperature program was used: at $60{ }^{\circ} \mathrm{C}$ the temperature was held for $5 \mathrm{~min}$, followed by ramp of $3{ }^{\circ} \mathrm{C} /$ min until $300{ }^{\circ} \mathrm{C}$, where it was maintained for $1 \mathrm{~min}$. The following chemicals were used in the experiments and quantification of the reaction products: guaiacol (Fluka, $\geq 98 \%), \quad(1 S, 2 S)$-2-methoxycyclohexanol (Aldrich), methoxycyclohexane (Tokyo Chemical Industry Co., $\geq 98 \%$ ), 2-methoxycyclohexanone (Tokyo Chemical Industry Co., >95\%), cyclohexanol (Sigma Aldrich, 99\%), phenol (Sigma Aldrich, 99\%), cyclohexane (LabScan, 99\%), cresol (Sigma Aldrich, $>98 \%$ ), anisole (Sigma Aldrich, > 99\%), 2-methoxy-4-methylphenol (Sigma Aldrich, $>98 \%$ ) and benzene (Sigma Aldrich, $>$ 99\%). The unknown reaction products were identified with GC-MS using a similar column and a method used with GC.

Conversion of guaiacol was defined as:

$X=\frac{c_{0, G}-c_{i, G}}{c_{0, G}} \cdot 100 \%$,

were $\mathrm{X}$ is conversion and $\mathrm{c}_{0, \mathrm{G}}$ and $\mathrm{c}_{\mathrm{i}, \mathrm{G}}$ are the concentrations of guaiacol at the beginning and at time $t$. The product selectivity (or molar fraction) is defined as moles of a product $\mathrm{P}$ divided by the sum of all products visible in GC: 
Molar fraction $=\frac{n_{P}}{\sum n_{P i}} \cdot 100 \%$.

It should be pointed out here that although guaiacol was in some cases converted rapidly, the products were not visible in chromatograms due to its oligomerisation. The sum of the masses of the reactant and products in the liquid phase (SMLP) determined by GC mass balance is defined as follows:

$S M L P=\frac{\sum m_{G i+P i_{i, G}}}{m_{0, G}} \cdot 100 \%$

i.e. the sum of the masses of guaiacol and all products visible in chromatograms at time $t$ divided by the initial mass of guaiacol.

\section{Results and Discussion}

\subsection{Catalyst Characterization Results}

The BET specific area of $40 \mathrm{wt} \% \mathrm{Mo}_{\mathrm{x}} \mathrm{C}-\mathrm{SBA}-15$ equal to $340 \mathrm{~m}^{2} / \mathrm{g}$ is in the same range as reported for $30 \mathrm{wt} \%$ $\mathrm{Mo}_{2} \mathrm{C}-\mathrm{SBA}-15$, which exhibited BET surface area of $403 \mathrm{~m}^{2} / \mathrm{g}$ [29]. The BET for the parent SBA-15 was $645 \mathrm{~m}^{2} / \mathrm{g}$. Mo $\mathrm{C}-\mathrm{SBA}-15$ was composed of both $50 \mathrm{wt} \%$ $\mathrm{Mo}_{2} \mathrm{C}$ and $50 \mathrm{wt} \% \mathrm{MoC}$ phases, with $\mathrm{MoC}$ exhibiting peaks at $36.4^{\circ}, 42.3^{\circ}, 61.3^{\circ}$ corresponding to (111), (200) and (220) faces [36] as denoted in XRD results (Fig. 1).

TEM images of the fresh and spent $40 \mathrm{wt} \% \mathrm{Mo}_{\mathrm{x}} \mathrm{C}-$ SBA-15 catalysts used in guaiacol $\mathrm{HDO}$ at $200{ }^{\circ} \mathrm{C}$ and $300{ }^{\circ} \mathrm{C}$ under 30 bar showed no sintering with the average crystallite particle sizes for both materials being in the range of 6.1-7.3 nm (Fig. 2). In the fresh $40 \mathrm{wt} \% \mathrm{Mo}_{\mathrm{x}} \mathrm{C}-$ SBA-15 catalysts some separate clusters with the size of
$140 \mathrm{~nm}$ outside SBA-15 matrix are visible, but their amount decreased in the spent catalyst, which was also indicated by energy-dispersive X-ray analysis (EDXA) analysis giving $\mathrm{Mo} / \mathrm{Si}$ ratio (discussed below).

The fresh and spent $5 \mathrm{wt} \% \mathrm{Pt} / \mathrm{C}$ catalysts contained well dispersed spherical Pt particles with the average particle size of 3.1 and $3.2 \mathrm{~nm}$, respectively indicating absence of sintering (Table 3; Fig. 3).

EDXA results showed that the $\mathrm{Mo} / \mathrm{Si}$ mass ratio decreased from the fresh $40 \mathrm{wt} \% \mathrm{Mo}_{\mathrm{x}} \mathrm{C}-\mathrm{SBA}-15$ from 1.0 to 0.88 when the catalyst was used in guaiacol HDO at $300{ }^{\circ} \mathrm{C}$ (Table 3). This might indicate that a part of molybdenum was removed from the catalyst by leaching.

Thermogravimetry is one of the methods to investigate coke on the catalyst surface. Analysis of the spent $\mathrm{Ru} / \mathrm{C}$ catalyst used in guaiacol HDO in [8] demonstrated maximally $35 \%$ weight loss from the spent catalyst in the temperature range of $100-1000{ }^{\circ} \mathrm{C}$ when the weight loss from the fresh catalyst was subtracted. In the current work the weight losses between 100 and $900{ }^{\circ} \mathrm{C}$ for the fresh and spent $40 \mathrm{wt} \% \mathrm{Mo}_{\mathrm{x}} \mathrm{C}-\mathrm{SBA}-15$ used in guaiacol transformation at $200{ }^{\circ} \mathrm{C}$ and $300{ }^{\circ} \mathrm{C}$ were 3,39 and $8 \%$, respectively, clearly showing that especially at $200^{\circ} \mathrm{C}$ a substantial amount of organic compounds was accumulated on the catalyst surface (Fig. 4a). In this case the catalyst was not very active, which will be further elaborated.

A commercial $5 \mathrm{wt} \% \mathrm{Pt} / \mathrm{C}$ (Degussa) was tested in this work for comparison. The metal dispersion and the cluster size were $36.2 \%$ and $3 \mathrm{~nm}$, respectively. The catalyst is slightly acidic as $\mathrm{pH}$ of the catalyst slurry is 5.6 [37]. The weight loss from the fresh $5 \mathrm{wt} \% \mathrm{Pt} / \mathrm{C}$ catalyst, which contains also water release, is $14 \%$ in the temperature range between 100 and $900{ }^{\circ} \mathrm{C}$, being $34 \%$ for the spent $5 \mathrm{wt} \% \mathrm{Pt} / \mathrm{C}$ catalyst applied in guaiacol transformation at $300{ }^{\circ} \mathrm{C}$ under 30 bar (Fig. 4).
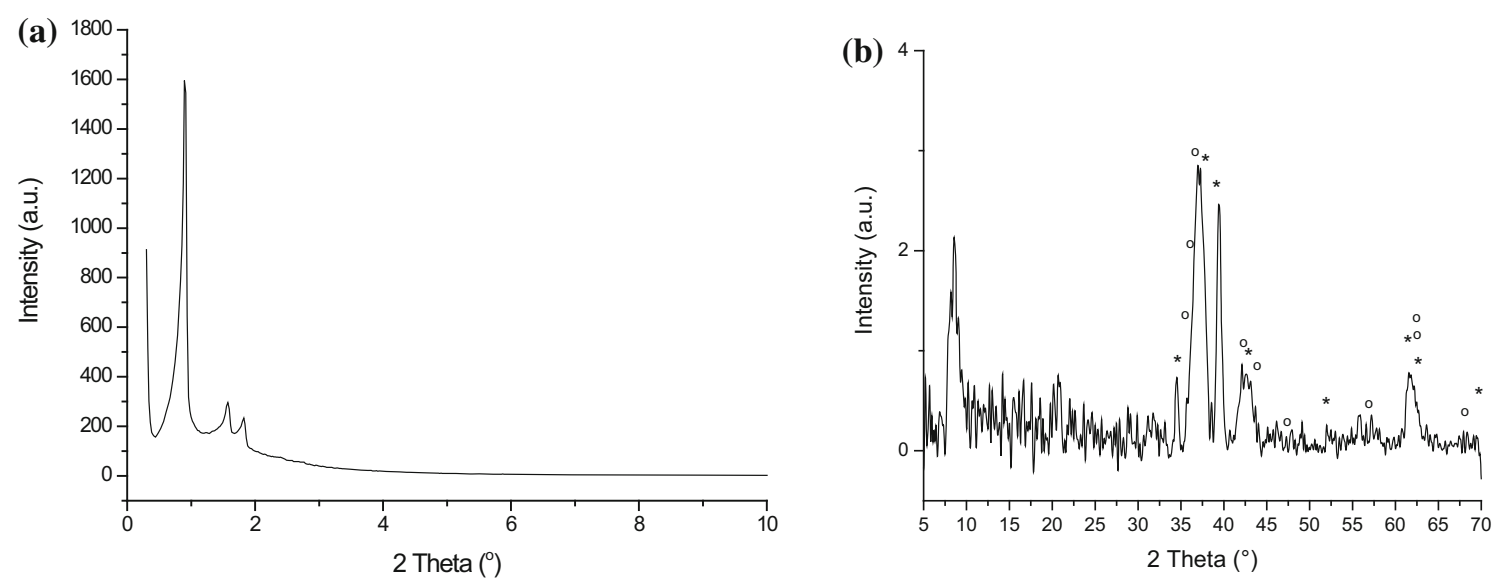

Fig. 1 Diffractograms of a SBA-15 and b $40 \mathrm{wt} \% \mathrm{Mo}_{\mathrm{x}} \mathrm{C}-\mathrm{SBA}-15$. Notation: (asterisks) $\mathrm{Mo}_{2} \mathrm{C}$ and (open circles) MoC phases. The diffraction peaks of $\mathrm{Mo}_{2} \mathrm{C}$ and $\mathrm{MoC}$ have been taken from PDFs 71-0242 and 89-4305, respectively 

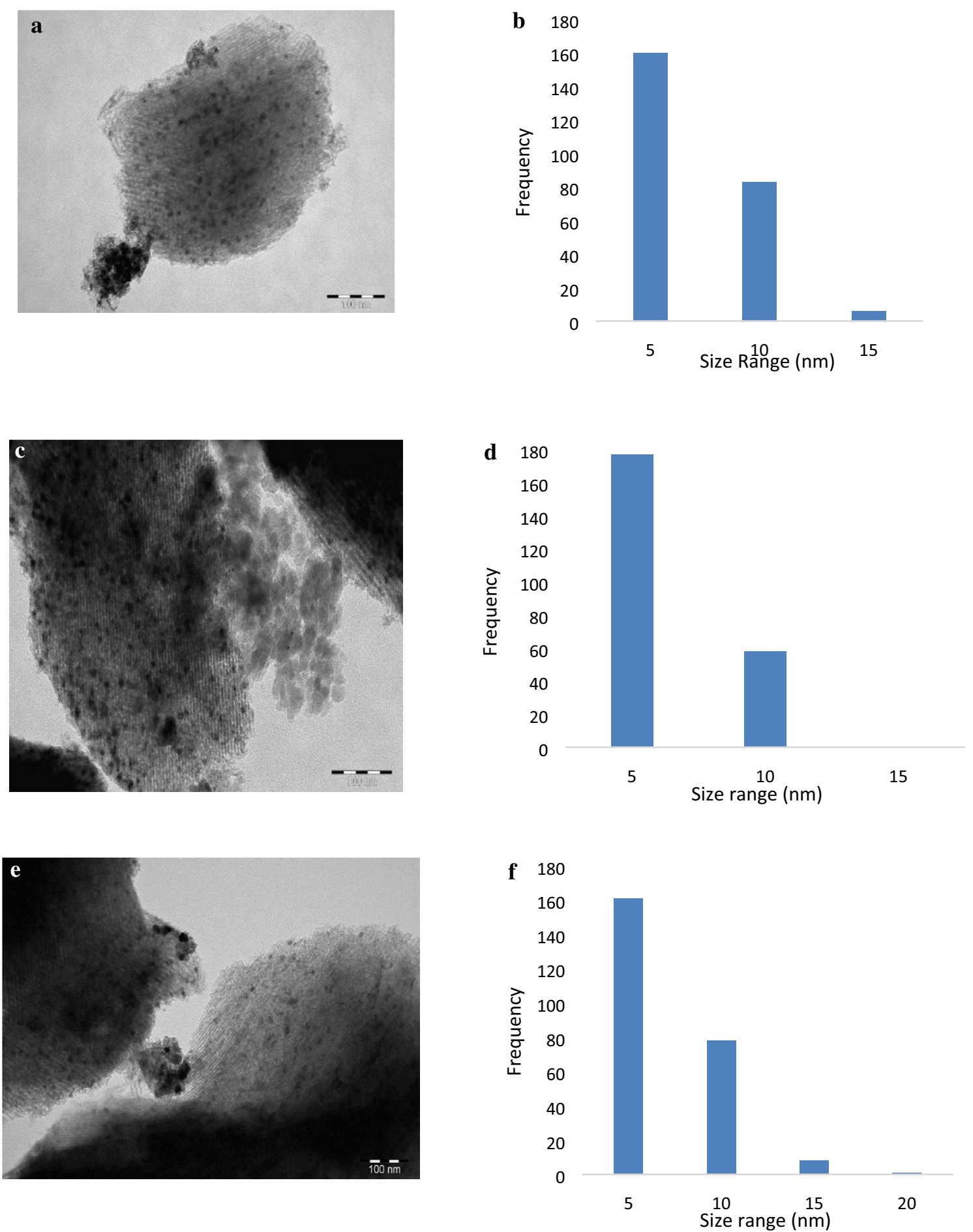

Fig. 2 Transmission electron microscopy images and histograms of the fresh (a and b), the spent (c and d) $40 \mathrm{wt} \% \mathrm{Mo}_{\mathrm{x}} \mathrm{C}-\mathrm{SBA}-15$ catalysts in the reaction of guaiacol at $200{ }^{\circ} \mathrm{C}$ under total pressure of

In this work coke was extracted from the spent catalysts used in guaiacol transformation at $200{ }^{\circ} \mathrm{C}$ under total pressure of 30 bar hydrogen with refluxing heptane for $4 \mathrm{~h}$ and analyzed by SEC (Fig. 5). The amount of extracted oligomers from the spent $40 \mathrm{wt} \% \mathrm{Mo}_{\mathrm{x}} \mathrm{C}-\mathrm{SBA}-15$ was

30 bar and $40 \mathrm{wt} \% \mathrm{Mo}_{\mathrm{x}} \mathrm{C}-\mathrm{SBA}-15$ catalysts (e and $\mathbf{f}$ ) in the reaction of guaiacol at $300{ }^{\circ} \mathrm{C}$ under total pressure of 30 bar. The scale bar is $100 \mathrm{~nm}$

high. When comparing the peaks in SEC chromatogram with the reference (polystyrene), it can be stated that the main oligomers over $\mathrm{Mo}_{\mathrm{x}} \mathrm{C}-\mathrm{SBA}-15$ contained mostly more than nine and five monomeric units. 
Table 3 Characterization results of the fresh and spent catalysts

\begin{tabular}{lllllll}
\hline Catalyst & \multicolumn{2}{l}{ Metal particle size TEM $(\mathrm{nm})$} & Specific surface area $\left(\mathrm{m}^{2} / \mathrm{g}_{\text {cat. }}\right)$ & Phases (XRD) & \multicolumn{2}{c}{ Mo/Si ratio (SEM-EDXA) } \\
\cline { 2 - 3 } & Fresh & Spent & & $\mathrm{Mo}_{2} \mathrm{C}, \mathrm{MoC}$ & $\mathrm{Mo} / \mathrm{Si}=1.0$ & $\mathrm{Mo} / \mathrm{Si}=0.88^{\mathrm{b}}$ \\
\hline $40 \mathrm{wt} \% \mathrm{Mo}_{2} \mathrm{C}-\mathrm{SBA}-15$ & 7.3 & $6.1^{\mathrm{b}}$ & 340 & & & Fresh \\
$5 \mathrm{wt} \% \mathrm{Pt} / \mathrm{C}$ & 3.1 & $3.0^{\mathrm{c}}$ & & n.d. & n.d. & n.d. \\
\hline
\end{tabular}

n.d. Not determined

${ }^{\text {a }}$ From the spent catalyst used in guaiacol transformation at $300{ }^{\circ} \mathrm{C}$

${ }^{\mathrm{b}}$ From the spent catalyst used in guaiacol transformation at $200{ }^{\circ} \mathrm{C}$

${ }^{\mathrm{c}}$ From the spent catalyst used in guaiacol transformation at $200{ }^{\circ} \mathrm{C}$
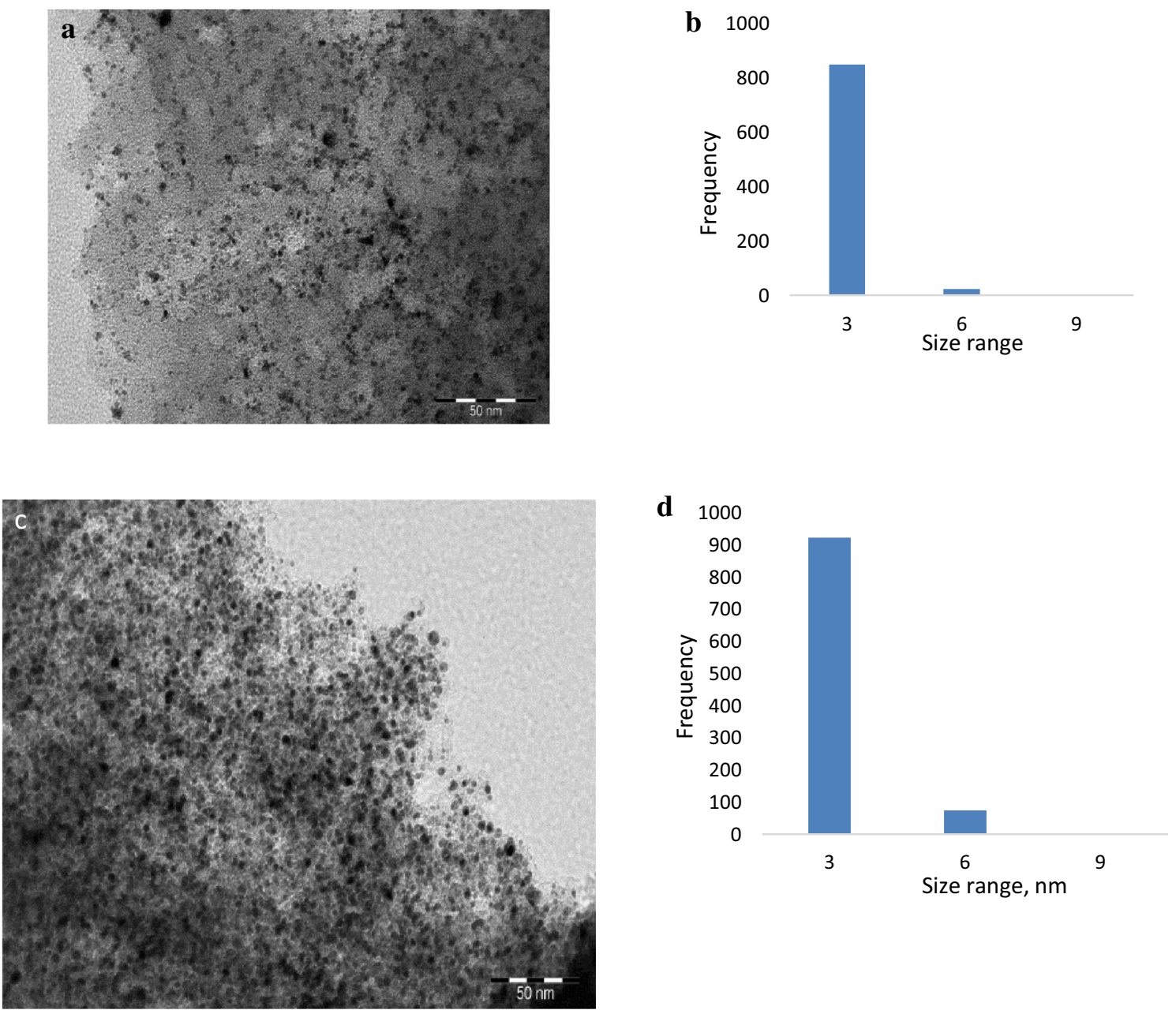

Fig. 3 Transmission electron microscopy images and histograms of the fresh (a and b) and spent (c and d) $5 \mathrm{wt} \% \mathrm{Pt} / \mathrm{C}$ catalysts in the reaction of guaiacol at $300{ }^{\circ} \mathrm{C}$ under 30 bar total pressure. The scale bar is $50 \mathrm{~nm}$

Extensive coking of $\mathrm{Mo}_{\mathrm{x}} \mathrm{C}-\mathrm{SBA}-15$ can be explained by high temperature used in the current work for deoxygenation of guaiacol. Furthermore, the main product was benzene (see below). Demethoxylation and reductive hydroxylation can thus lead to catalyst coking.

\subsection{Thermodynamic Analysis of Guaiacol Hydrodeoxygenation}

In order to reveal thermodynamic consistency of the experimentally observed results calculations of the Gibbs 

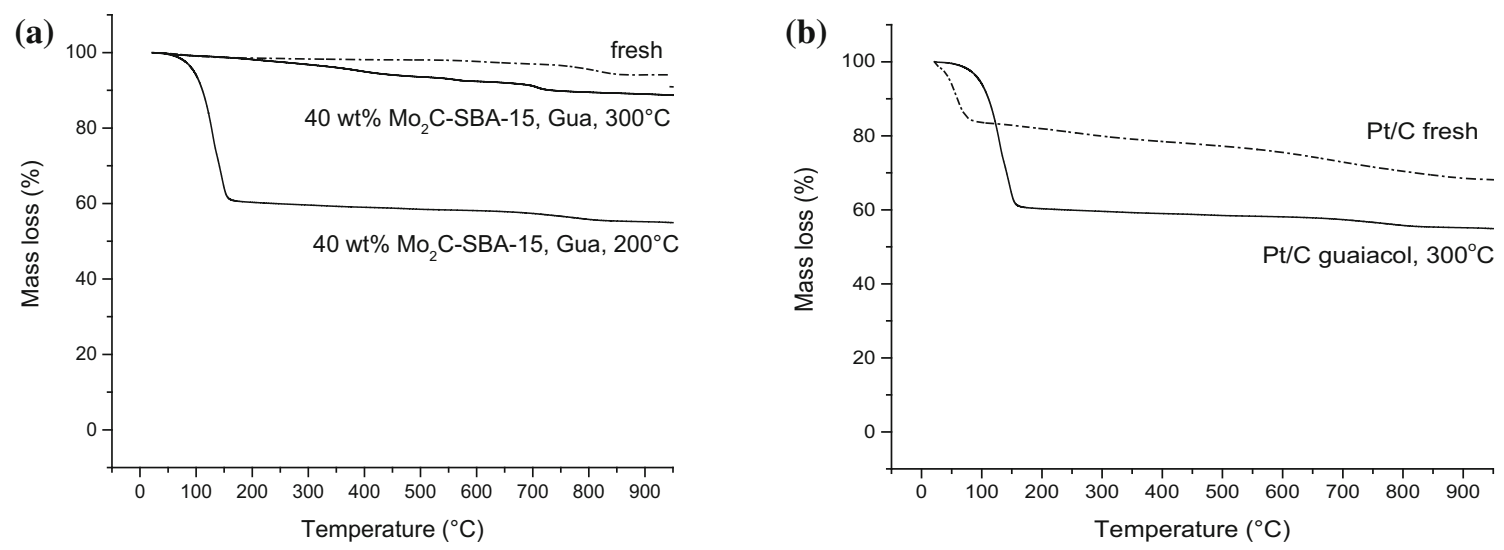

Fig. 4 Thermogravimetrical analysis (TGA) of the fresh and spent a $40 \mathrm{wt} \% \mathrm{Mo}_{\mathrm{x}} \mathrm{C}-\mathrm{SBA}-15$ and $\mathbf{b} 5 \mathrm{wt} \% \mathrm{Pt} / \mathrm{C}$

Fig. 5 Size exclusion chromatogram (SEC) of the extracted spent $40 \mathrm{wt} \% \mathrm{Mo}_{\mathrm{x}} \mathrm{C}-$ SBA-15. The catalyst was used in guaiacol transformation at $200{ }^{\circ} \mathrm{C}$ under 30 bar total pressure

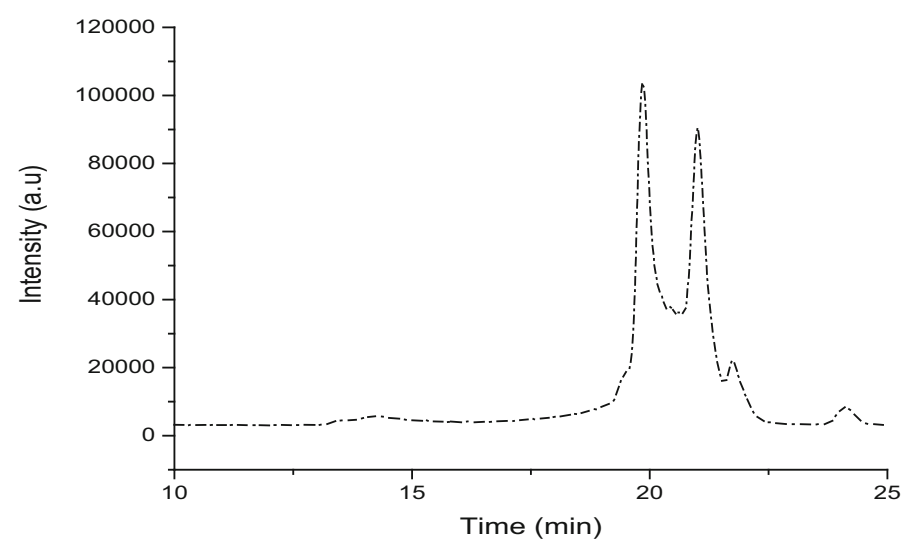

Finally, to calculate the $\Delta G_{r, j}$ at different pressures, the following equation was implemented.

$\Delta G_{r, j}(P)=\Delta G_{r, j}^{\Phi}+n R T \ln \left(\frac{P}{P^{0}}\right)$.

The calculated enthalpy and Gibbs free energy formation for each component are reported in Table 4. The data were retrieved from ChemCAD v.5.0 database directly. Starting from these values, the enthalpy and Gibbs free energy for each reaction $(j)$ at standard conditions, equilibrium constants at standard conditions $\left(K_{j}^{0}\right)$, enthalpy and Gibbs free energy at different temperatures and pressure were calculated. Two different temperatures were investigated $\left(T_{1}=473.15 \mathrm{~K}, T_{2}=573.15 \mathrm{~K}\right)$ and the energy values were calculated also at $P_{1}=25$ bar.

The most feasible reaction is hydrogenation of guaiacol to 2-methoxycyclohexanol in Table 4 (step 12) at $200{ }^{\circ} \mathrm{C}$ under 1 bar hydrogen followed by reductive dehydroxylation of cyclohexanol and 2-methoxycyclohexanol (steps 8 and 11). The effect of hydrogen pressure on Gibbs free energy is clearly visible at both temperatures, i.e. the reactions became less favorable with increasing hydrogen pressure for all reactions. Hydrogenation of phenol and 
Table 4 Enthalpy and Gibbs free energy for each reaction (j) (reaction numbers are shown in Scheme 1) at standard conditions, equilibrium constants at standard conditions $\left(K_{j}^{0}\right)$, enthalpy and Gibbs free energy at different temperatures and pressures $\left(\mathrm{T}_{1}=200{ }^{\circ} \mathrm{C}, \mathrm{T}_{2}=300{ }^{\circ} \mathrm{C}\right)$

\begin{tabular}{|c|c|c|c|c|c|c|c|}
\hline$j$ & $\Delta H_{r, j}^{0}(\mathrm{~kJ} / \mathrm{mol})$ & $\Delta G_{r, j}^{0}(\mathrm{~kJ} / \mathrm{mol})$ & $K_{j}^{0}$ & $\begin{array}{l}\Delta G_{r, j}^{\Phi}\left(T_{1}\right) \\
(\mathrm{kJ} / \mathrm{mol})\end{array}$ & $\begin{array}{l}\Delta G_{r, j}^{\Phi}\left(T_{2}\right) \\
(\mathrm{kJ} / \mathrm{mol})\end{array}$ & $\begin{array}{l}\Delta G_{r, j}\left(T_{1}, P_{1}\right) \\
(\mathrm{kJ} / \mathrm{mol})\end{array}$ & $\begin{array}{l}\Delta G_{r, j}\left(T_{2}, P_{1}\right) \\
(\mathrm{kJ} / \mathrm{mol})\end{array}$ \\
\hline 1 & -48.3 & -70.3 & $2.07 \times 10^{12}$ & -83.2 & -90.6 & -70.6 & -75.3 \\
\hline 2 & -62.5 & -66.3 & $4.15 \times 10^{11}$ & -68.6 & -69.8 & -55.9 & -54.5 \\
\hline 3 & -206 & $-9.78 \times 10^{4}$ & $1.35 \times 10^{17}$ & -34.3 & 19.3 & -21.7 & 17.3 \\
\hline 4 & 45.9 & $5.18 \times 10^{4}$ & $8.56 \times 10^{-10}$ & 55.2 & 57.2 & 67.9 & 72.5 \\
\hline 5 & -66.3 & $-7.47 \times 10^{4}$ & $1.21 \times 10^{13}$ & -79.6 & -82.4 & -67.0 & -67.1 \\
\hline 6 & -42.1 & $-4.34 \times 10^{4}$ & $4.00 \times 10^{7}$ & -44.1 & -44.6 & -31.5 & -29.2 \\
\hline 7 & -198 & $-8.52 \times 10^{4}$ & $8.51 \times 10^{14}$ & -19.0 & 18.8 & -0.635 & 34.2 \\
\hline 8 & -70.4 & $-78.9 \times 10^{4}$ & $6.57 \times 10^{13}$ & -83.9 & -86.7 & -71.2 & -71.4 \\
\hline 9 & -134 & $-83.9 \times 10^{4}$ & $5.04 \times 10^{14}$ & -54.3 & -37.4 & -41.7 & -22.1 \\
\hline 10 & -41.5 & 1.88 & $4.69 \times 10^{-1}$ & 27.4 & 41.9 & 40.0 & 57.3 \\
\hline 11 & -70.4 & -73.5 & $7.46 \times 10^{12}$ & -75.3 & -76.3 & -62.6 & -61.0 \\
\hline 12 & -418 & -310 & $2.48 \times 10^{54}$ & -248 & -212 & -235 & -196 \\
\hline 13 & -77.2 & -81.5 & $1.87 \times 10^{14}$ & -83.9 & -85.4 & -71.3 & -70.0 \\
\hline 14 & -60.8 & -81.3 & $1.75 \times 10^{14}$ & -93.4 & -100 & -80.7 & -84.9 \\
\hline 15 & -192 & -82.2 & $2.52 \times 10^{14}$ & -17.6 & 19.4 & -4.89 & 34.7 \\
\hline 16 & -63.5 & -70.9 & $2.62 \times 10^{12}$ & -75.2 & -77.7 & -62.5 & -62.3 \\
\hline 17 & -48.7 & -62.1 & $7.50 \times 10^{10}$ & -69.9 & -74.4 & -57.2 & -59.0 \\
\hline
\end{tabular}

benzene became also thermodynamically not feasible at $300{ }^{\circ} \mathrm{C}$ under 25 bar (steps 7, 3). Experimental determination of 2-methoxycyclohexanone in the reaction at $300{ }^{\circ} \mathrm{C}$ under 30 bar total pressure in the current work agrees well with the thermodynamic calculations for step 10 showing that hydrogenation of 2-methoxycyclohexanone is not feasible at $300{ }^{\circ} \mathrm{C}$ under 25 bar. Table 4 also illustrates that alkylation of phenol with (step 4) is thermodynamically not feasibly, while there are no thermodynamic restrictions for formation of cresol by transalkylation of phenol with guaiacol.

\subsection{Catalytic Results}

Supported on SBA-15 molybdenum carbide was investigated in guaiacol transformation at $200{ }^{\circ} \mathrm{C}$ under 30 bar total pressure not, however, giving any products visible in GC chromatograms. This indicates strong adsorption of guaiacol on the catalyst surface as also confirmed by TGA and SEC analysis. The sum of the masses of reactant and products in the liquid phase determined by GC results was therefore equal to zero (Table 5).

Supported $40 \mathrm{wt} \% \mathrm{Mo}_{\mathrm{x}} \mathrm{C}-\mathrm{SBA}-15$ was at the same time active at $300{ }^{\circ} \mathrm{C}$ giving the final conversion levels of $62 \%$ after $240 \mathrm{~min}$ (Table 5). The sum of the masses of the reactant and products in the liquid phase determined by GC for $40 \mathrm{wt} \% \mathrm{Mo}_{\mathrm{x}} \mathrm{C}-\mathrm{SBA}-15$ was only $37 \%$. When the solid material determined in TGA was added to the sum of the masses of the reactant and products in the liquid phase determined by GC, it was still only $40 \%$. These sums of the masses of reactant and products in the liquid phase determined by GC contain only compounds visible in the GC and the solid organic residue determined by TGA. In the extraction of the spent catalyst $40 \mathrm{wt} \% \mathrm{Mo}_{\mathrm{x}} \mathrm{C}-\mathrm{SBA}-15$ from guaiacol transformation at $200{ }^{\circ} \mathrm{C}$ large amounts of oligomers were observed. The sum of the masses of the reactant and products in the liquid phase determined by GC obtained for molybdenum carbide catalyst supported on SBA-15 in the current work in guaiacol transformation at $300{ }^{\circ} \mathrm{C}$ under 30 bar total pressure is lower than the one reported by Jongerius et al. [13], namely $72 \%$ at $350{ }^{\circ} \mathrm{C}$ under 55 bar of hydrogen over $\mathrm{Mo}_{2} \mathrm{C} / \mathrm{CNF}$. Higher sums of the masses of the reactant and products in the liquid phase determined by GC were reported in [2] in the range of $74-93 \%$ in guaiacol $\mathrm{HDO}$ in water as a solvent over $\mathrm{Mo}_{2} \mathrm{C}$ supported on active carbon at $300{ }^{\circ} \mathrm{C}$ under $137 \mathrm{bar}$ hydrogen. It has been reported that the mass balance closure increases with increasing hydrogen pressure [13], which is relatively low in the current work as compared to [13].

Concentration dependencies for guaiacol HDO over $40 \mathrm{wt} \% \mathrm{Mo}_{\mathrm{x}} \mathrm{C}-\mathrm{SBA}-15$ at $300{ }^{\circ} \mathrm{C}$ as well as selectivity dependence on conversion are given in Fig. 6. Guaiacol transformation was very rapid already during heating of the reaction mixture. Thereafter, the catalyst retained its activity during the course of the reaction.

The main product in guaiacol transformation over $40 \mathrm{wt} \% \mathrm{Mo}_{\mathrm{x}} \mathrm{C}-\mathrm{SBA}-15$ catalysts at $300{ }^{\circ} \mathrm{C}$ at the 
Table 5 Experimental results for guaiacol HDO

\begin{tabular}{|c|c|c|c|c|c|c|c|c|c|c|c|c|}
\hline Catalysts & $\mathrm{T}\left({ }^{\circ} \mathrm{C}\right)$ & $X$ & SMLP $^{\mathrm{a}}$ & $S_{\text {phenol }}^{\mathrm{b}}$ & $\mathrm{S}_{\text {cresol }}$ & $S_{\text {benzene }}$ & $\mathrm{S}_{\mathrm{IPB}}$ & $\mathrm{S}_{2 \mathrm{MCHOL}}$ & $\mathrm{S}_{2 \mathrm{MCHONE}}$ & $\mathrm{S}_{\mathrm{MCH}}$ & $\mathrm{S}_{\mathrm{CHOL}}$ & $\mathrm{S}_{\mathrm{CH}}$ \\
\hline Mo & 200 & 0 & 0 & 0 & 0 & 0 & 0 & 0 & 0 & 0 & 0 & 0 \\
\hline Mo & 300 & 62 & 37 & 15 & 0 & 71 & 0 & 0 & 0 & 0 & 4 & 10 \\
\hline $\mathrm{Pt}$ & 200 & 46 & 91 & 0 & 0 & 0 & 0 & 81 & 0 & 2 & 15 & 3 \\
\hline $\mathrm{Pt}$ & 300 & 98 & 95 & 0 & 0 & 0 & 0 & 69 & 26 & 0 & 5 & 0 \\
\hline
\end{tabular}

IPB isopropylbenzene, 2MCHOL 2-methylcyclohexanol, 2MCHONE 2-methylcyclohexanone, $M C H$ methylcyclohexane, $C H O L$ cyclohexanol, $\mathrm{CH}$ cyclohexane

${ }^{\mathrm{a}}$ At $60 \%$ conversion

${ }^{\mathrm{b}}$ Selectivity $(\mathrm{mol} \%)$ refers to $50 \%$ conversion

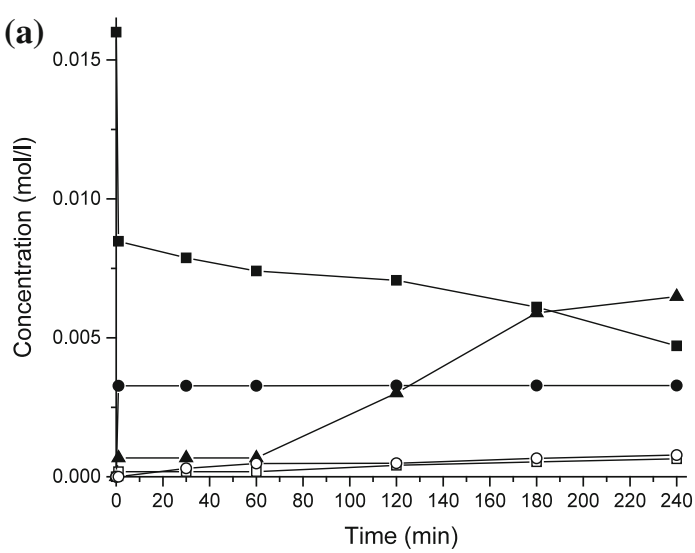

Fig. $6 \mathrm{HDO}$ of guaiacol over $40 \mathrm{wt} \% \mathrm{Mo}_{\mathrm{x}} \mathrm{C}-\mathrm{SBA}-15$ at $300{ }^{\circ} \mathrm{C}$ under 30 bar a concentration dependencies and $\mathbf{b}$ molar fraction of products as a function of conversion. Symbols: guaiacol (filled

beginning of the reaction was benzene, whereas its selectivity declined with increasing conversion and at the same time selectivity to phenol increased (Fig. 6b). Formation of phenol as the main product was also seen for $\mathrm{Mo}_{2} \mathrm{C} / \mathrm{CNF}$ [13]. On the other hand, cresol was the second major product [13], whereas no cresol was obtained in the current work over $40 \mathrm{wt} \% \mathrm{Mo}_{\mathrm{x}} \mathrm{C} / \mathrm{SBA}-15$. Formation of cresol requires transalkylation over acidic sites [39], which were not detected in this catalyst by ammonia TPD (not shown).

Selectivity towards aromatic products, phenol, and benzene decreased slightly from 94 to $86 \%$ during $4 \mathrm{~h}$ reaction when selectivity to cyclohexanol was increasing to a minor extent.

As a comparison to supported molybdenum carbide guaiacol HDO was also investigated over $5 \mathrm{wt} \% \mathrm{Pt} / \mathrm{C}$ both at $200{ }^{\circ} \mathrm{C}$ and $300{ }^{\circ} \mathrm{C}$. Guaiacol reacted at $200{ }^{\circ} \mathrm{C}$ very rapidly during heating of the reaction mixture, since its conversion was already $19 \%$ after $1 \mathrm{~min}$. The reaction rate between 1 and $120 \mathrm{~min}$ was $0.02 \mathrm{mmol} / \mathrm{min} / \mathrm{g}_{\text {cat }}$ after which the catalyst was completely deactivated and the final conversion remained at $46 \%$ level after $240 \mathrm{~min}$ (Fig. 7).

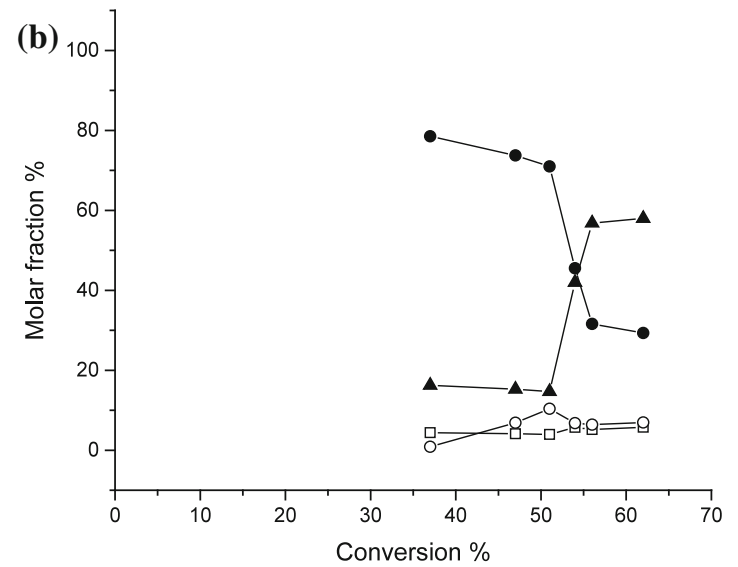

squares), phenol (filled triangles), benzene (filled circles), cyclohexanol (open squares), and cyclohexane (open circles)

This result is in accordance with the literature [10], reporting rapid guaiacol transformations at $250{ }^{\circ} \mathrm{C}$ with $87 \%$ conversion over Pt/C under 30 bar hydrogen. For Pd/ silica alumina catalyst there was no conversion of guaiacol at $200{ }^{\circ} \mathrm{C}$ under 30 bar hydrogen and this catalyst started to exhibit some activity at $230{ }^{\circ} \mathrm{C}$. In addition, PtPd-Al-HMS (mesoporous aluminosilicate) was active in guaiacol HDO surprisingly already at $200{ }^{\circ} \mathrm{C}$ under 50 bar hydrogen in $3 \mathrm{~h}$ in methanol as a solvent giving $80 \%$ conversion [26]. This result is not directly comparative with the current results due to the presence of methanol as a solvent and lower pressure. Transformations of guaiacol at $300{ }^{\circ} \mathrm{C}$ proceeded also very fast already during heating giving conversion of $51 \%$ in 1 min (Fig. 8). After the first minute the reaction rate was also very high, $0.06 \mathrm{mmol} / \mathrm{min} / \mathrm{g}_{\text {cat }}$ in the time range of 1 to $120 \mathrm{~min}$. Noteworthy is also that even after $240 \mathrm{~min}$ traces of guaiacol were visible in the $\mathrm{GC}$ analysis indicating catalyst deactivation.

The sums of the masses of the reactant and products in the liquid phase determined by $\mathrm{GC}$ obtained in guaiacol transformation at $200{ }^{\circ} \mathrm{C}$ and $300{ }^{\circ} \mathrm{C}$ over $5 \mathrm{wt} \% \mathrm{Pt} / \mathrm{C}$ were $91 \%$ and $95 \%$, respectively, reflecting minor 


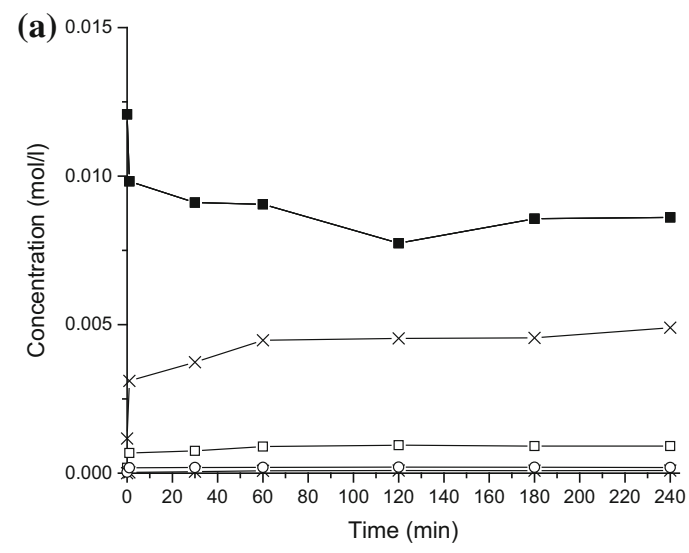

Fig. 7 Guaiacol transformation over $5 \mathrm{wt} \% \mathrm{Pt} / \mathrm{C}$ catalyst at $200{ }^{\circ} \mathrm{C}$ under 30 bar total pressure, a concentrations of different compounds and $\mathbf{b}$ molar fraction as a function of guaiacol conversion, notation for

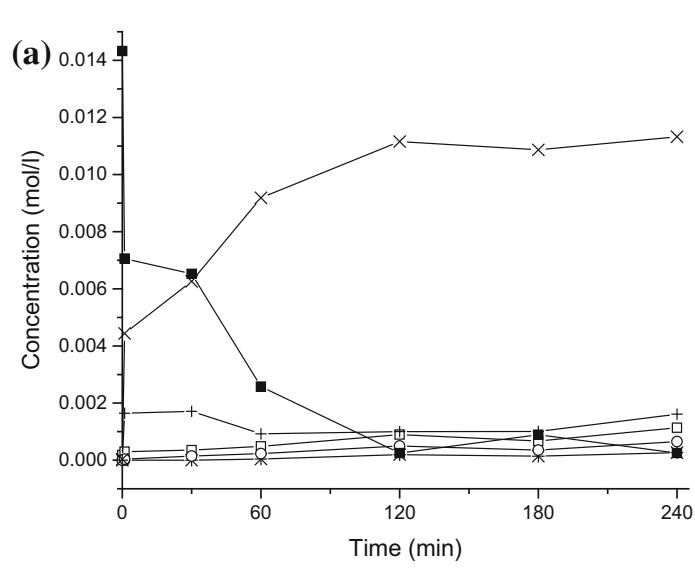

Fig. 8 Guaiacol $\mathrm{HDO}$ over $5 \mathrm{wt} \% \mathrm{Pt} / \mathrm{C}$ at $300{ }^{\circ} \mathrm{C}$ under 30 bar total pressure in hydrogen: $\mathbf{a}$ concentration profiles and $\mathbf{b}$ molar fraction of products as a function of guaiacol conversion. Notation: guaiacol (filled squares), phenol (filled triangles), cyclohexanol (open squares),

accumulation of some organic materials on the catalyst surface as also shown in TGA. When the sum of the masses of the reactant and products in the liquid phase determined by $\mathrm{GC}$ in guaiacol transformation over $5 \mathrm{wt} \% \mathrm{Pt} / \mathrm{C}$ was calculated taking into account both GC results from the liquid phase and TGA results, the sum of the masses of the reactant and products in the liquid phase determined by GC was $100 \%$. In addition, accumulation of organic material was more prominent at lower temperature, being aligned with the literature data on guaiacol transformation over $\mathrm{Mo}_{2} \mathrm{C} / \mathrm{CNF}$ catalyst [13]. For comparison, when Pt/C was used as a catalyst at $250{ }^{\circ} \mathrm{C}$ the guaiacol conversion was $87 \%$, and only totally $80 \%$ of products were observed [10].

The main product in guaiacol transformation over $5 \mathrm{wt} \% \mathrm{Pt} / \mathrm{C}$ was 2-methoxycyclohexanol both at $200{ }^{\circ} \mathrm{C}$ and $300{ }^{\circ} \mathrm{C}$ (Figs. 8, 9) analogously to the results in [10].

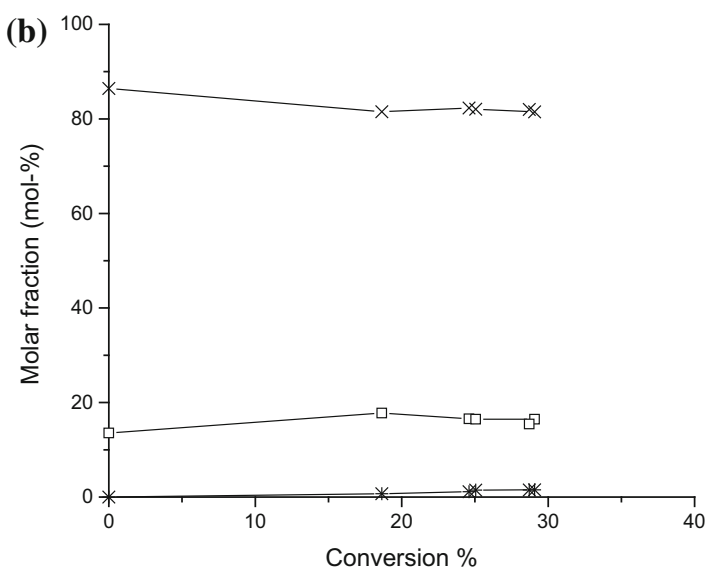

a and b guaiacol (filled squares), 2-methoxycyclohexanol (times), cyclohexane (open circles), 2-methoxycyclohexane (open squares), cyclohexanol (filled circles)

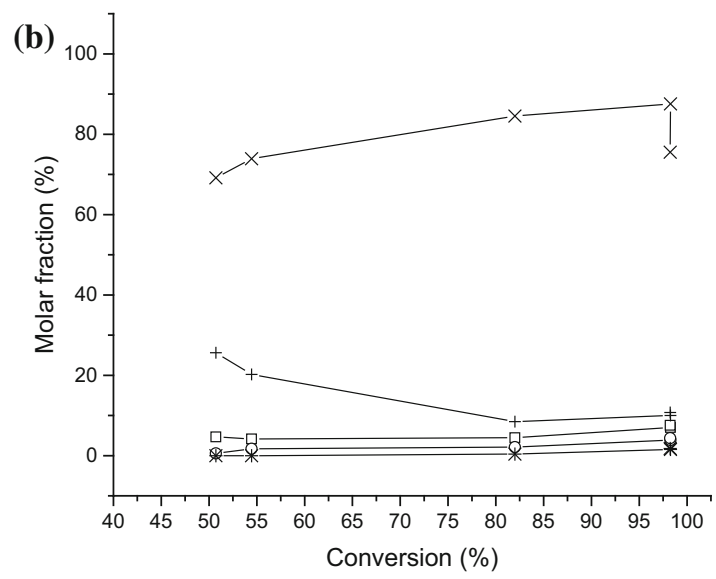

cyclohexane (open circles), methoxy-cyclohexanone (plus) and 2-methoxycyclohexanol (times) and 2-methoxycyclohexane (asterisks)

From the time dependent concentration profiles, it can also be seen that deoxygenation occurs to a minor extent since only low amounts of cyclohexane were formed. Relatively large amounts of 2-methoxycyclohexanone were formed at $300{ }^{\circ} \mathrm{C}$, whereas this intermediate was not visible at $200{ }^{\circ} \mathrm{C}$. For formation of 2-methoxycyclohexanone two routes could be proposed, either starting from dehydrogenation of 2-methoxycyclohexanol or alternatively directly from guaiacol via reversible hydrogenation-dehydrogenation analogously to phenol-cyclohexanone route [40]. Experimental results show that as expected it is thermodynamically more difficult to hydrogenate 2-methoxycyclohexanone at $300{ }^{\circ} \mathrm{C}$ compared to $200{ }^{\circ} \mathrm{C}$. Consecutive reactions, such as hydrogenolysis of 2-methoxycyclohexanol were not occurring to a large extent, which was also shown by thermodynamic analysis. The molar fraction of 2-methoxycyclohexanol remained at 


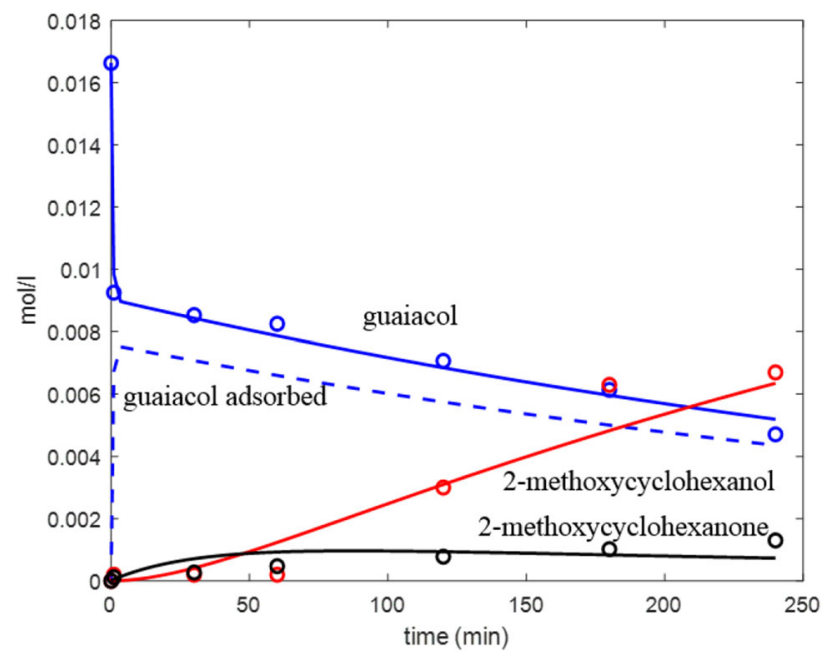

Fig. 9 Comparison of experimental and calculated data for HDO of guaiacol over $40 \mathrm{wt} \% \mathrm{Mo}_{\mathrm{x}} \mathrm{C}-\mathrm{SBA}-15$ at $300{ }^{\circ} \mathrm{C}$ under 30 bar

a constant level of $80 \%$ at $200{ }^{\circ} \mathrm{C}$ with increasing conversion (Fig. 7), whereas at $300{ }^{\circ} \mathrm{C}$ it decreased only slightly giving cyclohexanol via demethoxylation (Fig. 8; Scheme 1). At $200{ }^{\circ} \mathrm{C}$ selectivity to cyclohexanol was 2-fold higher compared to $300{ }^{\circ} \mathrm{C}$ indicating that demethoxylation occurs already at relatively low temperatures. Moreover, only minor amounts of cyclohexane (few $\%$ ), a fully deoxygenated product, were formed over $5 \mathrm{wt} \%$ $\mathrm{Pt} / \mathrm{C}$ catalyst. It can be concluded that a mildly acidic $5 \mathrm{wt} \% \mathrm{Pt} / \mathrm{C}$ promotes mainly hydrogenation of the phenyl ring thus consuming $3 \mathrm{~mol}$ of hydrogen per $1 \mathrm{~mol}$ of guaiacol and producing as the main product the non-oxygenated 2-methoxycyclohexanol.

A similar reaction pathway as mentioned above was observed for $40 \mathrm{wt} \% \mathrm{Mo}_{\mathrm{x}} \mathrm{C}-\mathrm{SBA}-15$ catalysts at $300{ }^{\circ} \mathrm{C}$ when guaiacol very fast gave a constant concentration of benzene followed by a gradual transformation of guaiacol to 2-methoxycyclohexanol. This part of the overall reaction network can be thus essentially simplified leading to

Guaiacol $_{\text {ads }} \leftrightarrow$ Guaiacol $\rightarrow 2$ - methoxycyclohexanone $\rightarrow 2$ - methoxycyclohexanol.

In Eq. (9) it is suggested that there is strong adsorption of guaiacol on the catalyst forming some sort of its reservoir on the surface, which explains a lack of mass balance closure in the liquid phase at the beginning of the reaction and its increase when the reaction proceeds. In essence hydrogenation of guaiacol to 2-methoxycyclohexanone and 2-methoxycyclohexanol shifts this equilibrium involving strongly adsorbed guaiacol in favor of hydrogenation. At the beginning of the reaction guaiacol concentration decreased very rapidly giving benzene and strongly adsorbed guaiacol. With increasing reaction time 2-methoxycyclohexanol started to be formed with increasing the mass balance closure. The latter compound displays a clear S-shaped behavior pointing out that 2-methoxycyclohexanone was formed as an intermediate.

The rates for this scheme are given as

$r_{G \rightarrow 2 M C H O}=\rho_{B} k_{G \rightarrow 2 M C H O} c_{G}$,

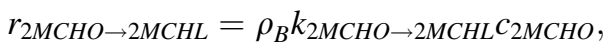

$r_{G \rightarrow G a d s}=\rho_{B} k_{G \rightarrow G a d s} c_{G}$,

$r_{G a d s \rightarrow G}=\rho_{B} k_{G a d s \rightarrow G} c_{G a d s}$,

where $\rho_{B}$ is the catalyst bulk density, G, Gads, $2 \mathrm{MCHO}$ and MCHL denote guaiacol, strongly adsorbed guaiacol, 2-methoxycyclohexanone and 2-methoxycyclohexanol.

The corresponding mass balances for each compound are given as

$\frac{d c_{G}}{d t}=-r_{G \rightarrow 2 M C H O}-r_{G \rightarrow G a d s}+r_{G a d s \rightarrow G}$,

$\frac{d c_{2 M C H O}}{d t}=r_{G \rightarrow 2 M C H O}-r_{2 M C H O \rightarrow 2 M C H L}$,

$\frac{d c_{2 M C H L}}{d t}=r_{2 M C H O \rightarrow 2 M C H L}$.

Because concentration of benzene did not change during the reaction it was included in modelling only indirectly. Namely the concentration of strongly adsorbed guaiacol was calculated by subtracting concentration of benzene, guaiacol, 2-methoxycyclohexanone and 2-methoxycyclohexanol from the initial concentration of guaiacol. The kinetic parameters were estimated using the backward difference method as a subtask to the parameter estimation with simplex and Levenberg-Marquardt methods implemented in software ModEst [41]. The objective function was defined as

$\theta=\sum\left(y_{i}-\hat{y}_{i}\right)^{2}$

and the coefficient of determination $\mathrm{R}^{2}$ is defined as

Table 6 The estimated parameters for hydrogenation of guaiacol over $40 \mathrm{wt} \% \mathrm{Mo}_{\mathrm{x}} \mathrm{C}-\mathrm{SBA}-15$ at $300{ }^{\circ} \mathrm{C}$ under $30 \mathrm{bar}$

\begin{tabular}{lll}
\hline Parameter & Estimate & Standard error $(\%)$ \\
\hline$\rho_{B} k_{2 M C H O \rightarrow 2 M C H L}$ & 0.0163 & 7.2 \\
$\rho_{B} k_{G \rightarrow 2 M C H O}$ & 0.0021 & 9.3 \\
$\rho_{B} k_{\text {Gads } \rightarrow G}$ & 0.6 & 93 \\
$\rho_{B} k_{G \rightarrow \text { Gads }}$ & 60.5 & 84 \\
\hline
\end{tabular}

Units of $\rho_{B} k_{i}$ are $\min ^{-1}$ 
$R^{2}=1-\frac{\sum\left(y_{i}-\hat{y}_{i}\right)^{2}}{\sum\left(y_{i}-\bar{y}_{i}\right)^{2}}$

in which $\bar{y}_{i}$ is the mean value of observations and $\hat{y}_{i}$ denotes model estimation. The calculated values of parameters along with standard errors are given in Table 6.

The model fit is shown in Fig. 9, illustrating a good overall description, which also follows from the value of the degree of explanation (97.22\%).

\section{Conclusions}

Kinetics of guaiacol HDO was investigated in a batch reactor using $40 \mathrm{wt} \% \mathrm{Mo}_{\mathrm{x}} \mathrm{C}-\mathrm{SBA}-15$ and $5 \mathrm{wt} \% \mathrm{Pt} / \mathrm{C}$ catalysts. Molybdenum carbide was prepared starting from hexamethylenetetramine molybdate as a precursor complex. Deposition of molybdenum carbide on SBA-15 resulted in both $\mathrm{MoC}$ and $\mathrm{Mo}_{2} \mathrm{C}$ phases and the specific surface area of $340 \mathrm{~m}^{2} / \mathrm{g}_{\text {cat. }}$. being more than 100 -fold higher than that for neat $\mathrm{Mo}_{2} \mathrm{C}$. The average $\mathrm{Mo}_{\mathrm{x}} \mathrm{C}$ particle size in the supported catalyst was $7.3 \mathrm{~nm}$.

Thermodynamic calculations according to the GibbsHelmholtz equation confirmed feasibility of guaiacol HDO to phenol in the range of $200-300{ }^{\circ} \mathrm{C}$, used for experiments. Exothermic hydrogenation reactions in the reactions network being thermodynamically feasible at $200{ }^{\circ} \mathrm{C}$ became unfeasible at higher temperatures.

A comparative investigation using $5 \mathrm{wt} \% \mathrm{Pt} / \mathrm{C}$ and $\mathrm{Mo}_{\mathrm{x}} \mathrm{C}$ as catalysts clearly showed that a non acidic $\mathrm{Pt} / \mathrm{C}$ catalyst was very active giving $98 \%$ conversion of guaiacol at $300{ }^{\circ} \mathrm{C}$ under $30 \mathrm{bar}$ total pressure during $240 \mathrm{~min}$. The main product with $5 \mathrm{wt} \% \mathrm{Pt} / \mathrm{C}$ was 2-methoxycyclohexanol indicating that it is not a suitable catalyst for production of hydrocarbons consuming also large amounts of hydrogen during hydrogenation of the aromatic ring. At the same time supported molybdenum carbide catalysts resulted in formation of phenol, benzene and cyclohexane in the liquid phase. Kinetic modelling was done quantitatively describing the concentration dependences with time.

Acknowledgements Open access funding provided by Abo Akademi University $(\mathrm{ABO})$. Lenka Pelíšková is acknowledged for performing XRD measurements.

Open Access This article is distributed under the terms of the Creative Commons Attribution 4.0 International License (http://creative commons.org/licenses/by/4.0/), which permits unrestricted use, distribution, and reproduction in any medium, provided you give appropriate credit to the original author(s) and the source, provide a link to the Creative Commons license, and indicate if changes were made.

\section{References}

1. Chang J, Danuthai T, Dewyiyanti S, Wang C, Borgna A (2013) Hydrodeoxygenation of guaiacol over carbon-supported metal catalysts. ChemCatChem 5:3041-3049

2. Santillan-Jimenez E, Perdu M, Pace R, Morgan T, Crocker M (2015) Activated carbon, carbon nanofiber and carbon nanotube supported molybdenum carbide catalysts for the hydrodeoxygenation of guaiacol. Catalysts 5:424-441

3. Sepúlveda C, Leiva K, García R, Radovic L, Ghampson I, DeSisto W, Fierro J, Escalona N (2011) Hydrodeoxygenation of 2-methoxyphenol over $\mathrm{Mo}_{2} \mathrm{~N}$ catalysts supported on activated carbons. Catal Today 172:232-239

4. Ghampson I, Sepúlveda C, Garcia R, Radovic L, Fierro J, DeSisto W, Escalona N (2012) Hydrodeoxygenation of guaiacol over carbon-supported molybdenum nitride catalysts: effects of nitriding methods and support properties. Appl Catal A 439-440:111-124

5. Ghampson IT, Sepuldeva C, Garcia R, Fierro JL, Escalona N (2016) Carbon nano-fiber supported $\mathrm{ReO}_{\mathrm{x}}$ catalysts for the hydrodeoxygenation of lignin-derived compounds. Catal Sci Technol 6:4356-4369

6. Cai Z, Wang F, Zhang X, Ahishakiye R, Xie Y, Shen Y (2017) Selective hydrodeoxygenation of guaiacol to phenolics over activated carbon supported molybdenum catalysts. Mol Catal 441:8-34

7. Sun J, Karim A, Zhang H, Kovarik L, Li X, Hensley A, McEwen J, Wang Y (2013) Carbon-supported bimetallic Pd-Fe catalysts for vapor-phase hydrodeoxygenation of guaiacol. J Catal 306:47-57

8. Gao D, Schweitzer C, Hwang H, Varma A (2014) Conversion of guaiacol on noble metal catalysts: reaction performance and deactivation studies. Ind Eng Chem Res 53:18658-18667

9. Liu X, Xu L, Xu G, Jia W, Ma Y, Zhang Y (2016) Selective hydrodeoxygenation of lignin-derived phenols to cyclohexanols or cyclohexanes over magnetic $\mathrm{CoN}_{\mathrm{x}} / \mathrm{NC}$ catalysts under mild conditions. ACS Catal 6:7611-7620

10. Deepa A, Dhepe P (2014) Function of metals and supports on the hydrodeoxygenation of phenolic compounds. ChemPlusChem 79:1573-1583

11. Zhao HY, Li D, Bui P, Oyama ST (2011) Hydrodeoxygenation of guaiacol as model compound for pyrolysis oil on transition metal phosphide hydroprocessing catalysts. Appl Catal A 391:305-310

12. Lee CR, Yoon JS, Suh YW, Choi J-W, Ha J-M, Suh DJ, Park YK (2012) Catalytic roles of metals and supports on hydrodeoxygenation of lignin monomer guaiacol. Catal Commun 17:54-58

13. Jongerius A, Gosselink R, Dijkstra J, Bitter J, Bruijnincx P, Weckhuysen B (2013) Carbon nanofiber supported transitionmetal carbide catalysts for the hydrodeoxygenation of guaiacol. ChemCatChem 5:2964-2972

14. Lu X, Zhu J, Li M, Shan Y, He M, Song C (2016) $\mathrm{TiO}_{2}$-modified $\mathrm{Pd} / \mathrm{SiO}_{2}$ for catalytic hydrodeoxygenation of guaiacol. Energy Fuels 30:6671-6676

15. Lu M, Du H, Wei B, Zhu J, Li M, Shan Y, Shen J, Song C (2018) Hydrodeoxygenation of guaiacol on $\mathrm{Ru}$ catalysts: influence of $\mathrm{TiO}_{2}-\mathrm{ZrO}_{2}$ composite oxides supports. Ind Eng Chem Res 56:12070-12079

16. Ma R, Cui K, Yang L, Ma X, Li Y (2015) Selective catalytic conversion of guaiacol to phenols over molybdenum carbide catalysts. Chem Commun 51:10299-10301

17. Nguyen T-S, Laurenti D, Afanasiev P, Konuspayeva Z, Piccolo L (2016) Titania-supported gold-based nanoparticles efficiently catalyze the hydrodeoxygenation of guaiacol. J Catal 344:136-140 
18. Tran NTT, Uemuyra Y, Chowdhury S, Ramli A (2016) Vaporphase hydrodeoxygenation of guaiacol on Al-MCM-41 supported $\mathrm{Ni}$ and Co catalysts. Appl Catal A 512:93-100

19. Peters JE, Carpenter JR, Dayton DC (2015) Anisole and guaiacol hydrodeoxygenation reaction pathway over selected catalysts. Energy Fuels 99:909-916

20. Olcese RN, Francois J, Bettahar MM, Petitjean D, Dufour A (2013) Hydrodeoxygenation of guaiacol, a surrogate of lignin pyrolysis vapors, over iron based catalysts: kinetic and modelling of the lignin to aromatic integrated process. Energy Fuels 27:975-984

21. Gonzalez-Borja M-A, Resasco DE (2011) Anisole and guaiacol hydrodeoxygenation over monolithic Pt-Sn catalysts. Energy Fuels 45:4155-4162

22. Mortensen PM, Grunwaldt J-D, Jensen PA, Knudsen G, Jensen AD (2014) Stability and resistance of nickel catalysts for hydrodeoxygenation: carbon deposition and effects of sulfur, potassium, and chlorine in the feed. Catal Sci Technol 4:3672-3686

23. Lee W-S, Wang Z, Wu RJ, Bhan A (2014) Selective vapor-phase hydrodeoxygenation of anisole to benzene on molybdenum carbide catalysts. J Catal 319:44-53

24. Zhang X, Zhang Q, Wang T, Ma L, Yu Y, Chen L (2013) Hydrodeoxygenation of lignin-derived phenolic compounds to hydrocarbons over $\mathrm{NiO}_{2}-\mathrm{ZrO}_{2}$-catalysts. Bioresour Technol 134:73-80

25. Lan X, Hensen EJM, Weber T (2018) Hydrodeoxygenation of guaiacol over $\mathrm{Ni}_{2} \mathrm{P} / \mathrm{SiO}_{2}$-reaction mechanism and catalyst deactivation. Appl Catal A 550:56-66

26. Roldugina EA, Naranov ER, Maximov AL, Karakhamov EA (2018) Hydrodeoxygenation of guaiacol as a model compound of bio-oil in methanol over mesoporous noble metal catalysts. Appl Catal A 553:24-33

27. Levy RB, Boudart M (1973) Platinum-like behavior of tungsten carbide in surface catalysis. Science 181:547-549

28. Garcia N, Esperanze B, Guzmán J, Tiemblo P, Morales V, García RA (2007) Functionalization of SBA-15 by an acid-catalyzed approach: a surface characterization study. Microporous Mesoporous Mater 106:129-139

29. Wu PY, Ji S-F, Hu LH, Zhu J-Q, Li C-Y (2008) Preparation, characterization, and catalytic properties of the $\mathrm{Mo}_{2} \mathrm{C} / \mathrm{SBA}-15$ catalysts. J Porous Mater 15:181-187
30. Chouzier S, Czeri T, Roy-Auberger M, Pichon C, Geante C, Vrinat M, Afanasiev P (2011) Decomposition of molybdatehexamethylenetetramine complex: one single source route for different catalytic materials. J Solid State Chem 184:2668-2677

31. Oh S, Hwang H, Choi HS, Choi JW (2014) Investigation of chemical modification of micro- and macromolecules in bio-oil during hydrodeoxygenation with $\mathrm{Pd} / \mathrm{C}$ catalyst in supercritical ethanol. Chemosphere 117:8106-8124

32. Zemansky MW, Abbott MM, Van Ness HC (1975) Basic engineering thermodynamics. McGraw-Hill, New York

33. Zukal A, Pastva J, Čejka J (2013) MgO-modified mesoporous silicas impregnated by potassium carbonate for carbon dioxide adsorption. Microporous Mesoporous Mater 167:44-50

34. Afanasiev P (2002) New single source route to the molybdenum nitride $\mathrm{Mo}_{2} \mathrm{~N}$. Inorg Chem 41:5317-5319

35. Abdullah HA, Hauser A, Ali FA, Al-Adwami A (2006) Optimal conditions for coke extraction of spent catalyst by accelerated solvent extraction compared to Soxhlet. Energy Fuels 20:320-323

36. Yan Z, Xie JL, Shen PK, Zhang ME, Chen M (2013) Pd supported on 2-4 nm MoC particles with reduced particle size, synergistic effect and high stability for ethanol oxidation. Electrochim Acta 108:644-650

37. Mäki-Arvela P, Tokarev A, Murzina E, Campo B, Heikkilä T, Brozinski J, Wolf D, Murzin DYu (2011) Kinetics of lactose and rhamnose oxidation over supported metal catalysts. Phys Chem Chem Phys 13:9268-9280

38. ChemCAD v.5.0. Chemstations. http://www.chemstations.com/. Accessed 15 May 2019

39. Zhu X, Lobban LL, Mallinson RG, Resasco RE (2011) Bifunctional transalkylation and hydrodeoxygenation of anisole over a Pt/HBeta catalyst. J Catal 281:21-29

40. Galvagno S, Donato A, Neri G, Pietropaolo RJ (1991) Hydrogenation of phenol to cyclohexanone over $\mathrm{Pd} / \mathrm{MgO}$. Chem Technol Biotechnol 51:145-153

41. Haario H (2011) ModEst, modelling and optimization software. ProfMath Oy, Helsinki

Publisher's Note Springer Nature remains neutral with regard to jurisdictional claims in published maps and institutional affiliations. 